Florence Nightingale Hemşirelik Dergisi

Florence Nightingale Journal of Nursing

FNJN Florence Nightingale Hemşirelik Dergisi 2017; 25(3): 193-200

Araştırma Makalesi / Research Article

ISNN e-dergi: 2147-8686 • ISNN print: 2147-4923

\title{
Yoğun Bakımdaki Çocuklarda Oral Mukozit Gelişme Durumu
}

\section{Development of Oral Mucositis in Patients in The Pediatric Intensive Care Unit}

\author{
Duygu Sönmez Düzkaya ${ }^{1}$, Gülzade Uysal ${ }^{2}$, Gülçin Bozkurt ${ }^{3}$, Tülay Yakut ${ }^{4}$
}

DOI: 10.17672/fnjn.343257

$15^{\text {th }}$ International Conference on Nursing $\&$ Midwifery (ICNM) Kongresi'nde sözel bildiri olarak sunulmuştur (24-25 Haziran 2017, Malezya)

${ }^{1}$ Dr., İstanbul Üniversitesi, İstanbul Tip Fakültesi, Hemşirelik Hizmetleri Müdürlüğü

istanbul, Türkiye

${ }^{2} Y$ rd. Doç. Dr., Okan Üniversitesi, Sağlık Bilimleri Fakültesi, Hemșirelik Bölümü, İstanbul, Türkiye ${ }^{3}$ Doç. Dr. İstanbul Üniversitesi, Sağıık Bilimleri Fakültesi, İstanbul, Türkiye

${ }^{4} \mathrm{Hem}$., İstanbul Üniversitesi, İstanbul Tip Fakültesi, Çocuk Yoğun Bakım Bilim Dalı, İstanbul, Türkiye

Sorumlu yazar/Corresponding author: Duygu Sönmez Düzkaya,

İstanbul Üniversitesi, İstanbul Tip Fakültesi, Hemșirelik Hizmetleri Müdürlüğü, Dekanlık Binası, Kat: 2, 34053, Fatih, İstanbul, Türkiye Telefon/Phone: +90 212414 2000/31458

E-posta/E-mail: dygsnmz@hotmail.com

Geliș tarihi/Date of receipt: 22.11.2016 Kabul tarihi/Date of acceptance: 07.08.2017

Atıf/Citation: Sönmez-Düzkaya, D., Uysal, G., Bozkurt, G. ve Yakut, T. (2017). Yoğun bakımdaki çocuklarda oral mukozit gelişme durumu. FNJN Florence Nightingale Hemşirelik Dergisi 25(3): 193-200.

https://doi.org/10.17672/fnjn.343257
ÖZ

Amaç: Araştırma, yoğun bakımındaki çocuklarda oral mukozit gelişme durumunu değerlendirmek amacıyla yapıldı.

Yöntem: Araştırma, Ocak-Aralık 2015 tarihleri arasında İstanbul'da bir üniversite hastanesinin çocuk yoğun bakım ünitesine yatışı yapıımış olan 181 çocuğun Mart -Nisan 2016 tarihleri arasında hasta dosyaları taranarak retrospektif olarak gerçekleştirilmiştir. Araştırma verileri, hasta dosyalarında yer alan bilgiler taranarak araştırıcılar tarafından toplanmıştır.

Bulgular: Hasta dosyalarından elde edilen veriler değerlendirildiğinde; çocukların yaş ortalamalarıın $48.69 \pm 3.29$ ay olduğu, \%37.5'inin solunum sistemi hastalığı tanısı ile yoğun bakımda yattığı, \%92.2'sinin oral beslenemediği, \%86.1'inin oksijen tedavisi ve \%77.3'ünün steroid tedavisi aldığı görüldü. Hastaların \%2.7'sinde oral mukozit oluştuğu, oral mukozit gelişen hastaların üçünün yoğun bakımdan taburcu olmadan iyileştiği, ikisinin ise 1. evre oral mukozit ile taburcu edildiği belirlendi.

Sonuç: Çalışmanın yürütüldüğü yoğun bakımdaki çocuklarda, risk faktörlerine rağmen, oral mukozit oranının düşük olduğu belirlendi.

Anahtar Kelimeler: Yoğun bakım, çocuk, oral mukozit

\section{ABSTRACT}

Aim: To evaluate the development of oral mucositis in patients admitted in the pediatric intensive care unit.

Method: Descriptive research was carried out by retrospectively scanning files of 181 children, who were admitted to the pediatric intensive care unit (ICU) of a university hospital in Istanbul between January and December, 2015. Rather than sampling, the whole population was included in the research. The data was extracted from patient files by the researchers.

Results: The mean age of the patients was $48.69 \pm 3.29$ months, $37.5 \%$ of the patients were treated in ICU because of respiratory system diseases, $92.2 \%$ could not manage oral feeding, $86.1 \%$ received oxygen therapy, and $77.3 \%$ received steroid treatment. Oral mucositis developed in $2.7 \%$ of patients, three patients fully recovered from oral mucositis before discharge from the ICU, and two patients were discharged with phase 1 oral mucositis

Conclusion: Although risk factors are prevalent in the ICU, the rate of oral mucositis was low among our patients.

Keywords: Intensive care, child, oral mucositis 


\section{EXTENDED ABSTRACT}

Introduction: Oral mucositis constitutes a potential risk in pediatric ICU, because of nosocomial infections and poor state of health of these children. Ensuring regular oral care for maintaining oral hygiene of the patients on mechanical ventilator in intensive care units is among significant nursing steps towards enhancing patients' comfort and quality of life. (Sebastian, Lodha, Kapil, \& Kabra, 2012; Sönmez-Düzkaya, 2014) Examining oral cavity (teeth, gingiva, tongue, mucous membrane, and lips) daily so as to avoid oral mucositis in ICU and providing oral care as per patients' requirements ensure good oral health by reducing dental plaque (Pearson, 2006). Oral health care, despite being a frequent nursing initiative with children in ICU, is not given adequate importance (Pearson, 2006). Information on standard nursing practices based on the prevalence of oral mucositis in children in ICU units and arriving at consensus about oral care is not sufficient (Çavuşoğlu, 2007; Grap, Munro, Brooke, \& Bryant, 2003; Yllmaz, 2007). The results of the research will provide cues regarding the rates of children developing oral mucositis under intensive care.

Aim: To evaluate the development of oral mucositis in patients in the pediatric care unit.

Method: Descriptive research was carried out by retrospectively scanning files of 181 children, admitted to the pediatric intensive care unit of a university hospital in Istanbul between January and December, 2015. Rather than sampling, the whole population was included in the research.

The data was extracted from patient files by researchers. In the unit, oral mucositis was evaluated daily in accordance with Oral Mucositis Evaluation Scale of World Health Organization (WHO), and the figures obtained were recorded in patients' files. Before collecting data, permissions were obtained from ethical committee and the institution in which the research was conducted. The data received in the research was analyzed by using descriptive statistical methods: figures, percentile, and average value.

Results: The average age of the children in the research group was $48.69 \pm 3.29$ months, $59.2 \%$ of whom were male, $37.5 \%$ had a respiratory disease and $66.8 \%$ were admitted to intensive care unit with an additional disease diagnosis. It was observed that $61.4 \%$ of the patients were intubated, $12.7 \%$ received parenteral nutrition, $74.5 \%$ were on antibiotics and $21 \%$ were treated with neuromuscular blocking drugs. It was seen that average period of the patients on ventilator was 4.54 \pm 3.01 days (range: 1-25 days) and the average length of stay in the pediatric ICU was $8.72 \pm 0.54$ days (range: $1-35$ days). On examining the risk factors with regards to oral mucositis, it was detected that $92.2 \%$ of the patients were not fed orally, $86.1 \%$ received oxygen therapy, 77.3\% received steroid therapy, $21.5 \%$ had fever, $18.2 \%$ developed dehydration and $4.4 \%$ received chemotherapy treatment. In line with the information acquired by patient files, oral mucositis was detected in $2.7 \%$ of the patients $(n=5)$; it was seen that two of these patients developed oral mucositis in the first 7 days of their admission to intensive care unit and three developed it 7 days after they were admitted to intensive care unit. It was seen that oral mucositis of three patients healed before being released from intensive care unit while two were discharged in first phase mucositis. It was seen that all patients developing oral mucositis were intubated, unable to be fed orally, received oxygen therapy, steroid therapy, antibiotics therapy and neuromuscular blocking drugs.

Conclusion: It was concluded that the rate of development of oral mucositis among children admitted to pediatric ICU is low, although, there exist many risk factors for mucositis in these children. Low rates of oral 
mucositis seen in this intensive care unit, where the research was conducted may be associated with the efficiency of nursing care or the fact that oral mucositis cases were not properly recorded. So as to discern between the two, conducting larger prospective studies is recommended. 


\section{Gíriş}

Yoğun bakım ünitelerine yatıştan 24-48 saat sonra, ağız florasının değiştiği, bakterilerin üremeye başladığı belirtilmektedir (Sebastian, Lodha, Kapil ve Kabra, 2012; Sönmez-Düzkaya, 2014). Ağız mukozasında; tükrük ve lgA salgısının azalması, nazogastrik sonda/ endotrakeal tüp (ETT) nedeniyle ağzın sürekli açık olması, steroid, sedatif ve opioid gibi tedavide kullanılan ilaçlar, ağızdan sıvı ve besin alamama, oksijen tedavisi, yüksek ateş, endotrakeal tüp tespiti için kullanılan flasterler, ağız ve çevresindeki doku bütünlüğünün bozulmasına yol açmaktadır (Özveren, 2010; Sebastian ve ark., 2012).

Oral mukozit ile ilgili çalışmalar daha çok erişkin hastalarda yapılmıştır. Erişkin hastalarda ETT takıldık$\tan 24$ saat sonra hastaların \%4.4'ünde ciddi düzeyde, \%41'inde orta düzeyde ağız mukozasının bütünlüğünün bozulduğu bildirilmiştir (Mohammed ve Hassan, 2015). Ullman, Long ve Lewis (2011) yoğun bakımdaki çocukların \%63'ünde orta düzeyde ağızda mukoza bütünlüğünün bozulduğunu saptamıştır.

Yoğun bakımda mekanik ventilatöre bağlı hastalar$\mathrm{da}$, oral hijyenin sağlanması, sürdürülmesi, hastanın konforunu ve yaşam kalitesini yükseltmeye yönelik önemli hemşirelik girişimleridir (Akdemir, 2013; Berry ve Davidson, 2006; Özveren, 2010). Yoğun bakımda oral mukoziti önlemek için günlük olarak oral kavitenin (diş, diş etleri, dil, mukoz membran ve dudaklar) değerlendirilmesi ve hastanın ihtiyacına göre ağız bakımının yapılmasının dental plağı azalttığı, ağız sağlığını koruduğu bildirilmektedir (Fields, 2008; Garcia ve ark., 2009; Pearson, 2006; Uysal ve Sönmez-Düzkaya, 2013). Yoğun bakımdaki çocuklarda ağız bakımı en sık yapılan hemşirelik girişimi olmakla birlikte yeterince önemsenmemektedir (Kearns, Brewer ve Booth, 2009).

Hemşireler yoğun bakımdaki hastalara ağız bakımı yaparak mukozitin önlenmesi, şiddetinin azaltılması ve hastaların yaşam kalitesinin yükselmesinde aktif rol alırlar. Yoğun bakımdaki çocuklarda oral mukozit görülme sıklığı ve ağız bakımına yönelik üzerinde görüş birliğine varılan kanıta dayalı standart bakım uygulamaları ile ilgili veriler yetersizdir. Çocuk yoğun bakım ünitelerinin gelişimi ülkemizde yenidir. Dolayısı ile ülkemizde ve dünya genelinde yoğun bakımdaki çocuklar ile ilgili yapılan çalışmalar sınırlıdır. Çalışma sonuçları yoğun bakımdaki çocuklarda oral mukozit gelişmesinin önlenmesi açısından değerli ipuçları sağlayacaktır (Çavuşoğlu, 2007; Grap, Munro, Brooke ve Bryant, 2003; Yılmaz, 2007).

Bu çalışma, yoğun bakımdaki çocuklarda oral mukozit gelişme durumunu değerlendirmek amacıyla yapıldı.

\section{YÖNTEM}

\section{Araştırmanın Tipi}

Çalışma retrospektif ve tanımlayıcı nitelikte gerçekleştirildi.

\section{Araştırmanın Evreni ve Örneklemi}

Çalışma Ocak-Aralık 2015 tarihleri arasında, İstanbul'da bir üniversite hastanesinin, çocuk yoğun bakım ünitesine yatışı yapılmış olan 181 hastanın Mart -Nisan 2016 tarihleri arasında dosyaları incelenerek yapılmıştır. Araştırmada örneklem seçimine gidilmemiş, evrenin tamamı araştırmaya dahil edilmiştir.

Araştırmanın yürütüldüğü Çocuk Yoğun Bakım Ünitesi 6 yatak kapasitesine sahiptir. Ünitede 13 hemşire, 4 hekim (2 rotasyonel asistan, 1 profesör, 1 uzman), 1 temizlik personeli, 5 hasta bakıcı ve 1 tıbbi sekreter olmak üzere toplam 24 kişi çalışmaktadır. Üniteye akut solunum yetmezliği, sepsis, şok, multi-organ yetmezliği, zehirlenme, post-operatif yakın izlem vb. hastalıkları olan yılda ortalama 150-250 çocuk kabul edilmektedir.

\section{Veri Toplama Araçları ve Verilerin Toplanması}

Veriler, araştırıcılar tarafından hasta dosyaları taranarak toplanmıştır. Hasta dosyaları klinik hemşireleri tarafından hastalar değerlendirildikten sonra doldurulmaktadır. Araştırmanın yapıldığı ünitede hastalara ait "Genel Hasta Dosyası" ve "Günlük Değerlendirme Dosyası" olmak üzere iki dosya yer almaktadır. Genel 
hasta dosyasından hastayı tanılamak için gerekli bilgiler (yaş, cinsiyet, tanı, ek hastalıklar vb.) alınmıştır. Günlük değerlendirme dosyasından ise, hastanın beslenme durumu, mekanik ventilasyon uygulanmasına ve kullanılan ilaçlar gibi bireysel özellikleri içeren, oral mukozit risk faktörlerine yönelik veriler toplanmıştır. Ayrıca hemşireler tarafından Dünya Sağlık Örgütü (DSÖ) Oral Mukozit Değerlendirme Ölçeği doğrultusunda yapılan oral mukozit değerlendirmesinin puanları da dosyadan alınmıştır.

\section{Dünya Sağlık Örgütü (DSÖ) Oral Mukozit} Değerlendirme Ölçeği: Dünya Sağlık Örgütü tarafından önerilen ve hastanelerde oral mukozitin derecelendirmesinde kullanılan bir tanımlama aracıdır. Ölçekte oral mukozaya ilişkin anatomik değişiklikler ve mukozit şiddeti "sıfır" ile "dört" arasında puanlanmaktadır. Mukozit yok ve ağız sağlıklı görünümde (0), eritem ve oral kavitede lezyonlar görülür (1), mukozada kırmızı alanlar artmış, lezyonlar birbirinden ayrı (2), oral mukozanın tamamı kırmızı ve çok sayıda birleşmiş ülser görülür (3), ağızda ülserasyon, hemoraji ve nekroz var ise (4) puan verilerek derecelendirilmektedir (Can, 2007; Cheng, Molassiotis, Chang, Wai ve Cheung, 2001; Çubukçu, 2005).

\section{Araştırmanın Etik Yönü}

Veri toplamaya başlamadan önce araştırmanın yapıldığı kurumdan (11.02.2016) ve etik kuruldan (Etik kurul tarihi: 29.02.2016, onay numarası: 74) yazılı izinler alınmıştır.

\section{Verilerin Değerlendirilmesi}

Araştırmada elde edilen verilerin analizi SPSS (Statistical Package for Social Sciences) 21.0 paket programında sayı, yüzde ve ortalama değerlerle analiz edildi.

\section{BULGULAR}

Araştırma grubundaki çocukların yaş ortalamalarının 48.69ะ3.29 ay olduğu, \%59.2'sinin erkek olduğu, \%37.5'inin solunum sistemi hastalığı ve \%66.8'inin ek bir hastalık tanısı ile yoğun bakımda yatmış olduğu, \%61.4'ünün entübe olduğu, \%12.7'sinin parenteral beslendiği, \%74.5'inde antibiyotik, \%21'inde ise nöromüsküler bloke edici ilaç kullanmış olduğu belirlendi. Hastaların ortalama mekanik ventilasyon süresinin 4.54 2.01 gün (1-25 gün), ortalama yoğun bakımda kalış süresinin ise $8.72 \pm 0.54$ gün (1-35 gün) olduğu görüldü (Tablo 1).

Oral mukozit açısından risk faktörleri incelendiğinde; \%92.2'sinin oral beslenmediği, \%86.1'inin oksijen tedavisi aldığı, \%77.3'ünün steroid tedavisi aldığı, \%21.5'inin yüksek ateşinin olduğu, \%18.2'sinde dehidratasyon geliştiği ve \%4.4'ünün kemoterapi tedavisi aldığı saptandı (Tablo 2).

Hasta dosyalarından elde edilen bilgiler doğrultusunda hastaların \%2.7'sinde oral mukozit geliştiği,

Tablo 1. Hastaları tanıtıcı özellikler $(\mathrm{N}=181)$

\begin{tabular}{|c|c|c|}
\hline Özellikler & $\mathbf{n}$ & $\%$ \\
\hline Yaş (ay) Ortalama & $48.69 \pm 3.29$ & \\
\hline \multicolumn{3}{|l|}{ Cinsiyet } \\
\hline KIZ & 74 & 40.8 \\
\hline Erkek & 107 & 59.2 \\
\hline \multicolumn{3}{|l|}{ Tanı } \\
\hline Solunum sistemi hastalıkları & 68 & 37.5 \\
\hline Nörolojik sistem hastalıkları & 39 & 21.5 \\
\hline Sepsis & 24 & 13.3 \\
\hline Post-op izlem & 17 & 9.4 \\
\hline İntoksikasyon & 15 & 8.4 \\
\hline Metabolik hastalıklar & 13 & 7.2 \\
\hline Diğer hastalıklar & 5 & 2.7 \\
\hline \multicolumn{3}{|l|}{ Ek Hastalıklar } \\
\hline Var & 101 & 66.8 \\
\hline Yok & 80 & 33.2 \\
\hline \multicolumn{3}{|l|}{ Hastaların Beslenme Durumu } \\
\hline Oral & 15 & 8.2 \\
\hline Enteral & 24 & 13.3 \\
\hline Parenteral & 23 & 12.7 \\
\hline Enteral + Parenteral & 119 & 65.8 \\
\hline \multicolumn{3}{|l|}{ Entübasyon Durumu } \\
\hline Entübe & 111 & 61.4 \\
\hline Entübe değil & 70 & 38.6 \\
\hline \multicolumn{3}{|l|}{ Antibiyotik Tedavisi } \\
\hline Aliyor & 135 & 74.5 \\
\hline Almıyor & 48 & 25.5 \\
\hline \multicolumn{3}{|l|}{ Nöromüsküler Bloke Edici İlaç Tedavisi } \\
\hline Aliyor & 38 & 21 \\
\hline Almiyor & 143 & 79 \\
\hline $\begin{array}{l}\text { Mekanik Ventilasyon Süresi Ortalama } \\
\text { (min-max) }\end{array}$ & $4.54 \pm 3.01$ & $(1-25)$ \\
\hline $\begin{array}{l}\text { Yoğun Bakımda Kalış Süresi Ortalama } \\
\text { (min-max) }\end{array}$ & $8.72 \pm 0.54$ & $(1-35)$ \\
\hline
\end{tabular}


Table 2. Oral mukozit gelişmesi açısından olası risk faktörleri $(\mathrm{N}=181)$

\begin{tabular}{lcc}
\hline Risk Faktörleri & $\mathbf{n}$ & \% \\
\hline Oral beslenemeyen & 167 & 92.2 \\
Oksijen tedavisi alan & 156 & 86.1 \\
Steroid tedavisi alan & 140 & 77.3 \\
Yüksek ateşi olan & 39 & 21.5 \\
Dehidratasyon gelişen & 33 & 18.2 \\
Kemoterapi alan & 8 & 4.4 \\
\hline
\end{tabular}

edici ilaç tedavisi aldığı görüldü. Çocukların \%60'ının yüksek ateşi ve dehidratasyonunun olduğu, \%40'ının kemoterapi tedavisi aldığı belirlendi (Şekil 1).

\section{TARTIŞMA}

Yoğun bakımda çocukların ağız florasının bozulma riskinin birçok nedenle yüksek olduğuna dikkat çekilmektedir (Franklin, Senior, James ve Roberts, 2000;

Table 3. Oral mukozite ilişkin özellikler $(n=5)$

\begin{tabular}{|c|c|c|c|c|}
\hline Özellikler & $\begin{array}{c}\text { Dudak Kenarı } \\
\text { n (\%) }\end{array}$ & $\begin{array}{c}\text { Yanak İçi } \\
\text { n (\%) }\end{array}$ & $\begin{array}{l}\text { Dil Üstü } \\
\text { n (\%) }\end{array}$ & $\begin{array}{c}\text { Toplam } \\
\text { n (\%) }\end{array}$ \\
\hline \multicolumn{5}{|l|}{ Tanılama Evresi } \\
\hline 1.evre & - & - & $1(100)$ & $1(100)$ \\
\hline 2.evre & $1(25.0)$ & $2(50.0)$ & $1(25.0)$ & $4(100)$ \\
\hline \multicolumn{5}{|l|}{ Mukozit Oluşma Zamanı } \\
\hline$\leq 7 g u ̈ n$ & $1(50.0)$ & - & $1(50.0)$ & $2(100)$ \\
\hline$>7$ gün & - & $2(66.6)$ & $1(33.3)$ & $3(100)$ \\
\hline \multicolumn{5}{|l|}{ Taburculukta Mukozit } \\
\hline Mukozit var (1.evre) & $1(50.0)$ & - & $1(50.0)$ & $2(100)$ \\
\hline Mukozit yok & - & $2(40.0)$ & $1(20.0)$ & $3(100)$ \\
\hline
\end{tabular}

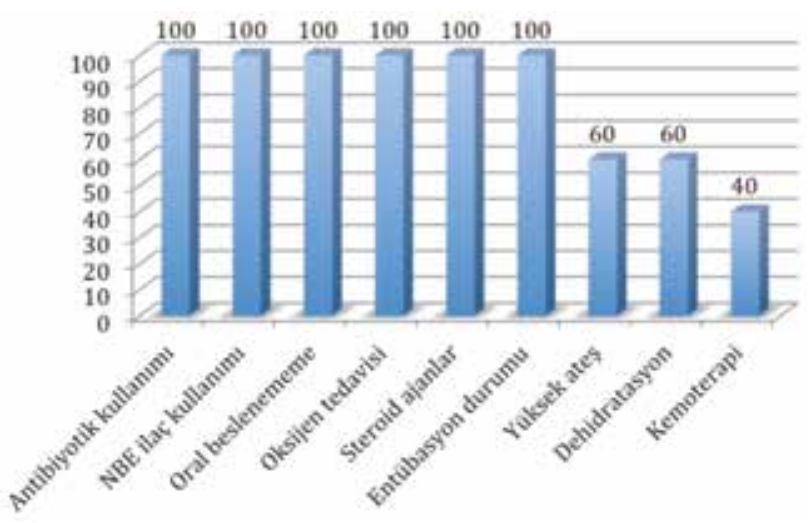

NBE ilaç kullanımı: Nöromüsküler bloke edici ilaç kullanımı

Şekil 1. Oral mukozit görülen hastaların özellikleri $(n=5)$

hastaların ikisinde yoğun bakıma yatışının ilk yedi gününde, üçünde ise yatıştan yedi gün sonra oral mukozit geliştiği görüldü. Oral mukozit gelişen hastaların üçünün yoğun bakımdan taburcu olmadan oral mukozitinin iyileştiği, ikisinin ise 1. evre oral mukozit ile taburcu edildiği belirlendi (Tablo 3).

Oral mukozit görülen hastaların tamamının; entübe olduğu, oral beslenemediği, oksijen tedavisi, steroid tedavisi, antibiyotik tedavisi ve nöromüsküler bloke
Özveren, 2010). Çocuklarda mukozit görülme sıklığının \%5-15 arasında değiştiği, kanser tedavisi gören çocuklarda bu oranın \%80'in üzerine çıktığı bildirilmektedir (Çavuşoğlu, 2007). Yoğun bakımdaki çocuklarda ise oral mukozit görülme sıklığına ilişkin yapılan çalışmalar oldukça sınırlıdır (Franklin ve ark., 2000; Ullman ve ark., 2011). Ullman ve ark. (2011) 46 çocuk hastada yaptığı çalışmada çocukların \%63'ünde ağız mukozasının bozulduğunu saptamıştır. Çalışma grubumuzdaki çocuklarda \%2.7 oranında oral mukozit gelişmiştir. Ullman ve ark. (2011) çalışmasının sonucu ile kıyaslandığında, çalışma grubumuzdaki çocuklarda oral mukozitin oldukça düşük olduğu söylenebilir. Çalışmanın yürütüldüğü yoğun bakımda oral mukozit oranın düşük olması, hastaların bakıma yönelik sorunlarının yeterince kayıt altına alınmamış olması veya hemşirelik bakımının etkinliği ile ilişkili olabilir. Ancak mevcut veriler ile bunu ayırt etmek mümkün değildir. Daha büyük örneklem gruplarında prospektif yapılmış çalışmalara gereksinim vardır.

Yoğun bakımda çocuklara yapılan girişimlerin (Grap ve ark., 2003; Özveren, 2010; Sebastian ve 
ark., 2012; Thorburn ve ark., 2009; Ullman ve ark., 2011), oral beslenememe, antibiyotik ve steroid kullanımı (Jiggins ve Talbot, 1999; Sixou, MedeirosBatista ve Bonnaure-Mallet, 1996) vb. oral mukozit riskini artırdığı, özellikle entübasyon tüpünün mukoza ve yanakta yaralanmalara yol açarak hastaların konforunu bozduğu bildirilmektedir (Ullman ve ark., 2011). Çalışma grubundaki oral mukozit görülen hastaların tamamının; entübe, oral beslenemeyen, oksijen tedavisi, steroid ve antibiyotik tedavisi alan hastalar olması literatür ile uyumludur. Oral mukozit gelişen hasta sayısı çok düşük olduğu için istatistiksel ilişki bakılamamıştır.

Hastaların yoğun bakımda kalış süresi uzadıkça kullanılan ilaç miktarının artması ve entübasyon süresinin uzamasına bağlı olarak ağız içi ve çevresinde doku bütünlüğünün bozulduğu bildirilmektedir (Özveren, 2010; Sebastian ve ark., 2012). Ullman ve ark. (2011) çalışmalarında yoğun bakımda yatıştan ortalama 4.4 gün sonra çocuklarda ağız mukozasının bozulduğunu saptamıştır. Çalışma grubumuzda oral mukozit görülen, toplam beş çocuğun üçünde yoğun bakıma yatıştan yedi gün sonra oral mukozit geliştiği belirlendi. Oral mukozit saptanan çocuk sayısı çok az olduğu için yoğun bakımda kalış süresi ile oral mukozit gelişmesi arasında istatistiksel ilişkiye bakılamamıştır. Çocuklarda yoğun bakımda kalış süresi ile mukozit gelişme ilişkisinin irdelendiği daha büyük örneklem de yapılmış, çok merkezli çalışmalara hâlâ ihtiyaç vardır.

Hasta dosyalarından elde edilen bilgilere göre, oral mukozit gelişen çocukların üçünde mukozitin tamamen iyileştiği, iki çocuğun ise birinci evre mukozit ile yoğun bakımdan taburcu edilmiş olduğu görüldü. Oral mukozit gelişen çocuklarda etkin bir ağız bakımı ile oral mukozitin önlenebileceği/tedavi edilebileceği bilinmektedir (Johnston, Spence ve Koziol-McLain, 2010; Thomson, Ayers ve Broughton, 2003). Çocukların mukozite bağlı yaşam kalitesinin etkilendiği, tedavi sürecinin uzadığı ve maliyet düşünüldüğünde mukozitin önlenmesi amaçlanmalıdır.

\section{SONUÇ VE ÖNERILER}

Oral mukozit yoğun bakımda hastane enfeksiyonları ve çocuğun genel sağlığı açısından potansiyel risk oluşturmaktadır. Çalışmanın yürütüldüğü yoğun bakımdaki çocuklarda mukozit açısından birçok risk faktörleri olmasına rağmen oral mukozit oranının düşük olduğu belirlendi.

\section{Araştırmanın Sınırlılıkları}

Çalışmanın verileri bir yoğun bakım ünitesinden alındığı için sonuçlar genellenemez. Oral mukozit gelişen hasta sayısı az olduğu için risk faktörleri açısından analizler yapılmadı. Yoğun bakımdaki çocuklarda yapılan oral mukozit ile ilgili çalışmaların sınırlı olması bulguların tartışılmasını sınırlandırdı.

\section{Teşekkür}

$15^{\text {th }}$ International Conference on Nursing \& Midwifery (ICNM) Kongresi'nde sözel bildiri olarak sunulmuştur (24-25 Haziran 2017, Malezya). Kongre katılımı "İstanbul Üniversitesi Bilimsel Araştırma Projeleri Birimi" tarafından Bilimsel Etkinliklere Katılım Desteği ile sağlanmıştır. I. Ü. BAP birimine destekleri için teşekkür ederiz.

\section{Kaynaklar}

Akdemir, N. B. (2013). Hastaların yoğun bakım deneyimleri ve etkileyen faktörlerin belirlenmesi (Yayınlanmamış Yüksek Lisans Tezi). Gazi Üniversitesi Sağlık Bilimleri Enstitüsü, Ankara.

Berry, A. M., \& Davidson, P. M. (2006, December). Beyond comfort: Oral hygiene as a critical nursing activity in the intensive care unit. Intensive Crit Care Nurs, 22(6), 318-328.

Can, G. (Ed.). (2007). Onkoloji hemşireliğinde kanıta dayalı semptom yönetimi. İstanbul: Medikal Yayıncılık.

Cheng, K. K., Molassiotis, A., Chang, A. M., Wai, W. C., \& Cheung, S. S. (2001). Evaluation of an oral care protocol intervention of chemotherapy-induced oral mucositis in paediatric cancer patients. European Journal of Cancer, 37(16), 2056-2063.

Çavuşoğlu, H. (2007). Oral mukozit yönetiminde kanıta dayalı hemşirelik. Türkiye Klinikleri Tip Bilimleri Dergisi, 27(3), 398406.

Çubukçu, Ç. E. (2005). Pediatrik kanser hastalarında oral mukozit ve ağız sağlığı. Güncel Pediatri, 3, 67-69. 
Fields, L. (2008). Oral care intervention to reduce incidence of ventilator associated pneumonia in the neurologic intensive care unit. Journal of Neuroscience Nursing, 40(5), 291-298.

Franklin, D., Senior, N., James, I., \& Roberts, G. (2000). Oral health status of children in a paediatric intensive care unit. Intensive Care Medicine, 26(3), 319-324.

Garcia, R., Jendresky, L., Colbert, L., Bailey, A., Zaman, M., \& Majumder, M. (2009). Reducing ventilator-associated pneumonia through advanced oral-dentalcare: A 48-month study. American Journal of Critical Care, 18(6), 523-534.

Grap, M. J., Munro, C., Brooke, A., \& Bryant, S. (2003). Oral care interventions in critical care: Frequency and documentation. American Journal of Critical Care, 12(2), 113-118.

Johnston, L., Spence, D., \& Koziol-McLain, J. (2010). Oral hygiene care in the pediatric intensive care unit: Practice recommendations. Pediatric Nursing, 36(2), 85-96.

Jiggins, M., \& Talbot, J. (1999). Mouthcare in PICU. Paediatric Nursing, 11(10), 23-26.

Kearns, R., Brewer, \& A., Booth, M. (2009). Oral hygiene practices in Scottish intensive care units- a national survey. Journal of Intensive Care Society, 10(2), 155-158.

Mohammed, H. M., \& Hassan, M. S. (2015). Endotracheal tube securements: Effectiveness of three techniques among orally intubated patients. Egyptian Journal of Chest Diseases and Tuberculosis, 64(1), 183-196.

Özveren, H. (2010). Mekanik ventilatöre bağlı hastalarda ağız bakımı. Hacettepe Üniversitesi Sağlık Bilimleri Fakültesi Hemşirelik Dergisi, 17(2), 92-99.

Pearson, L. S. (2006). A comparison of the ability of foam swabs and tooth brushes to remove dental plaque: Implications for nursing practice. Journal of Advanced Nursing, 23(1), 62-69.
Sebastian, M. R., Lodha, R., Kapil, A., \& Kabra, S. K. (2012). Oral mucosal decontamination with chlorhexidine for the prevention of ventilator-associated pneumonia in children a randomized, controlled trial. Pediatric Critical Care Medicine, 13(5), 305-310.

Sixou, J., Medeiros-Batista, O., \& Bonnaure-Mallet, M. (1996). Modifications of the microflora of the oral cavity arising during immunosuppressive chemotherapy. Oral Oncology: European Journal of Cancer, 32(5), 306-310.

Sönmez-Düzkaya, D. (2014). Pediatri yoğun bakımda ventilatör ilişkili pnömoninin önlenmesinde hemşirenin rolü. The Journal of Pediatric Research, 1(2), 54-61.

Thomson, W. M., Ayers, K. M. S., \& Broughton, J. R. (2003). Child oral health inequalities in New Zealand: A background paper to the Public Health Advisory Committee (pp.29-94). Retrieved from http://www.aapd.org/assets/1/7/ NZImprovingChildOralHealth.pdf.

Thorburn, K., Jardine, M., Taylor, N., Reilly, N., Sarginson, R. E., \& van Saene, H. K. (2009). Antibiotic resistant bacteria and infection in children with cerebralpalsy requiring mechanical ventilation. Pediatric Critical Care Medicine, 10(2), 222-226.

Ullman, A., Long, D., \& Lewis, P. (2011). The oral health of critically ill children: An observational cohort study. Journal of Clinical Nursing, 20(21-22), 3070-3080.

Uysal, G. ve Sönmez-Düzkaya, D. (2013). Çocuk yoğun bakım ünitelerinde kanıta dayalı uygulamalar. Yoğun Bakım Hemşireliği Dergisi, 17(1), 29-36.

Yılmaz, M. Ç. (2007). Mukozit yönetiminde kanıta dayalı uygulamalar. Uluslararası Hematoloji-Onkoloji Dergisi, 17(4), 241-246. 